\title{
Association between KRAS mutation and lung metastasis in advanced colorectal cancer
}

\begin{abstract}
A A L Pereira*,1, J F M Rego ${ }^{1}$, V Morris ${ }^{2}$, M J Overman ${ }^{3}, C$ Eng $^{3}$, C R Garrett ${ }^{3}$, A T Boutin ${ }^{4}$, R Ferrarotto ${ }^{5}$, M Lee ${ }^{2}$, Z-O Jiang ${ }^{3}$, P M Hoff ${ }^{1}$, J-N Vauthey $^{6}$, E Vilar $^{7}$, D Maru ${ }^{8}$ and S Kopetz ${ }^{3}$

${ }^{1}$ Department of Radiology and Oncology, Instituto do Cancer do Estado de São Paulo (ICESP) Universidade de São Paulo, São Paulo 01246, Brazil; ${ }^{2}$ Hematology and Oncology Fellow, The University of Texas MD Anderson Cancer Center, Houston, TX 77030, USA; ${ }^{3}$ Department of Gastrointestinal Medical Oncology, The University of Texas MD Anderson Cancer Center, Houston, TX 77030, USA; ${ }^{4}$ Department of Genomic Medicine, The University of Texas MD Anderson Cancer Center, Houston, TX 77030, USA; ${ }^{5}$ Department of Thoracic and Head and Neck Medical Oncology, The University of Texas MD Anderson Cancer Center, Houston, TX 77030, USA; ${ }^{6}$ Department of Surgical Oncology, The University of Texas MD Anderson Cancer Center, Houston, TX 77030, USA; ${ }^{7}$ Department of Clinical Cancer Prevention, The University of Texas MD Anderson Cancer Center, Houston, TX 77030, USA and ${ }^{8}$ Department of Pathology, The University of Texas MD Anderson Cancer Center, Houston, TX 77030, USA
\end{abstract}

Background: KRAS mutations have been associated with lung metastases at diagnosis of metastatic colorectal cancer (mCRC), but the impact of this mutation on subsequent development of lung metastasis is unknown. We investigated KRAS mutation as a predictor of lung metastasis development.

Methods: We retrospectively evaluated data from patients with $\mathrm{mCRC}$ whose tumour was tested for KRAS mutation from 2008 to 2010. The relationships of KRAS mutational status with time-to-lung metastasis (TTLM) and overall survival (OS) were analysed.

Results: Of the 494 patients identified, 202 (41\%) had tumours with KRAS mutation. KRAS mutations were associated with a shorter TTLM (median 15.2 vs 22.4 months; hazard ratio $=1.40 ; P=0.002$ ) and a two-fold greater odds of developing lung metastases during the disease course in patients with liver-limited $m C R C$ at diagnosis ( $72 \mathrm{vs} 56 \%, P=0.007$ ). Overall survival did not differ by KRAS status.

Conclusions: Lung metastasis was more likely to develop during the disease course in patients whose tumour had a KRAS mutation than in those whose tumour did not have a KRAS mutation. This finding may have an impact on decision making for surgical resection of metastatic disease.

Despite advances in treatment, metastatic colorectal cancer (mCRC) remains the fourth most common cause of cancer death worldwide (Siegel et al, 2013). The lung is the most common extraabdominal site of metastasis (Mitry et al, 2010).

Currently, the presence of KRAS mutation is the most important established predictive biomarker for resistance to antiepidermal growth factor receptor (EGFR) antibodies cetuximab and panitumumab (Siena et al, 2009). The KRAS protein functions as an essential component of the EGFR signalling cascade. Activating mutations in the KRAS gene cause the constitutive activation of Ras GTPase, which leads to the overactivation of downstream Raf/Erk/Map kinase and other signalling pathways, resulting in cell transformation and tumorigenesis (Leevers and Marshall, 1992; Wood et al, 1992). Preclinical studies have suggested that constitutively activated mutant KRAS can promote tumour invasion and metastasis by stimulating matrix metalloproteases, cysteine proteases, serine proteases and urokinase plasminogen activator, all of which facilitate migration through the basement membrane (Jankun et al, 1991; Buo et al, 1995; Yamamoto et al, 1995). The association between KRAS mutational 
status and prognosis is controversial: some studies have reported a link between KRAS mutations and poor prognosis (Lievre et al, 2006; Nash et al, 2010), whereas others have reported no association (Etienne-Grimaldi et al, 2008; Roth et al, 2010).

The pattern of CRC recurrence is partly determined by clinicopathologic features, such as primary tumour location, initial TNM stage or preoperative serum carcinoembryonic antigen level (Manfredi et al, 2006; Mitry et al, 2010; Watanabe et al, 2013). However, there are limited data evaluating whether the somatic mutation profile can have a role in the pattern of spread of metastasis in CRC patients. The few previous trials have suggested that KRAS mutations may influence and contribute to differences in the pattern of metastatic dissemination (Cejas et al, 2009; Tie et al, 2011; Kim et al, 2012). Although these studies focused on the prevalence of lung metastases, there is a clinical need for predictors of subsequent lung metastases in patients with no evidence of pulmonary involvement at the time of diagnosis of metastatic disease. We aimed to determine the potential value of KRAS mutation as a predictive factor for development of lung metastasis.

\section{PATIENTS AND METHODS}

Patient population. Patients with mCRC with known KRAS status who were treated at The University of Texas MD Anderson Cancer Center from 2008 through 2010, independent of metastatic site or whether they developed metastatic disease to the lung, were selected from a prospectively maintained institutional database. A total of 494 patients were identified. The study was approved by institutional review board and ethics committee.

Study end points. The primary end point of this retrospective study was a comparison of the time-to-lung metastasis (TTLM). This endpoint was defined as the time from diagnosis of metastatic disease, that is, from the first metastasis in any site, to the time of the first lung metastasis, between patients whose primary tumour had no KRAS mutation $\left(K R A S^{\text {wt }}\right)$ and patients whose tumour had a KRAS mutation (KRAS $\left.{ }^{\mathrm{mut}}\right)$. The secondary end point aimed to compare the pattern of lung involvement between these two groups and included the following dichotomous variables: lung as first site of metastasis, presence of lung metastasis at the end of follow-up, number of lung metastases (isolated vs multiple), lung lobes involved $(1 \quad v s>1)$, unilateral vs bilateral lung involvement, thoracic lymph node involvement (positive $v s$ negative) and synchronous vs metachronous or absent lung metastasis. Synchronous metastasis was defined as metastasis diagnosed before or up to 60 days after diagnosis of primary tumour. Overall survival (OS), defined as time from the first metastasis to death from any cause, and lung metastasis-free survival (LMFS), defined as time from the first metastasis in any site to the first lung metastasis or death, also were evaluated as secondary end points. All time-toevent analyses were calculated from the time of diagnosis of metastatic disease to be consistent with time-to-event analyses commonly reported for metastatic patients. It also reflects that this cohort was collected based on their documented development of metastatic disease.

KRAS mutation determination. KRAS mutations (codons 12,13 , 61; Supplementary Table 1) were identified in formalin-fixed, paraffin-embedded tissue by Sanger sequencing or mass spectroscopy genotyping (Sequenom, San Diego, CA, USA) in the U.S. Department of Health and Human Services Clinical Laboratory Improvement Amendments (CLIA)-compliant pathology lab as part of standard-of-care testing for the patients. Microdissection was utilised under the guidance of a clinical pathologist as required to ensure $>30 \%$ tumour cellularity.
Statistical methods and considerations. Patient characteristics and disease factors were summarised by descriptive statistics. The categorical parameters were compared by using the two-sided Pearson $\chi^{2}$-test or Fisher exact test, as appropriate, and the $t$-test was used for continuous variables. Time-to-event variables were calculated from the time of diagnosis of first metastasis in any site according to the Kaplan-Meier method and were compared by means of the log-rank test. SPSS software (version 16.0; SPSS, Chicago, IL, USA) was used for statistical analyses. A $P$-value $<0.05$ was considered significant.

\section{RESULTS}

Patient characteristics. Of the 494 patients included in this study, 203 (41\%) were female. Median follow-up was 26 months. The median age was 55 years (range, 25-85 years). KRAS mutation was identified in 202 of the tumours (KRAS $\left.{ }^{\text {mut }}, 41 \%\right)$, and 292 tumours were $K R A S$ wild type $\left(K R A S^{\mathrm{wt}}, 59 \%\right)$. The groups were unbalanced according to location of primary tumour; tumours with a KRAS mutation occurred more frequently in the right side of the colon $\left(K R A S^{\text {mut }} 43 \%\right.$ vs KRAS ${ }^{\mathrm{wt}} 28 \%$ ) than in the left colon or rectum (57 vs $71 \%, P=0.001)$. Other patient and disease characteristics are shown in Table 1.

Lung and liver metastases pattern. At the time of diagnosis of primary tumour, $60(12 \%)$ patients had synchronous lung involvement $\left(16 \%\right.$ of the KRAS ${ }^{\text {mut }}$ patients vs $9 \%$ of $\left.K R A S^{\mathrm{wt}}\right)$, representing a 1.9-fold greater odds of lung metastasis in the $K_{R A S^{\text {mut }}}$ population $(P=0.018,95 \%$ confidence interval $(\mathrm{CI})$ $1.08-3.42)$. The lung was the first site of metastatic disease in $18 \%$ of the KRAS ${ }^{\text {mut }}$ patients and $15 \%$ of the $K R A S^{\text {wt }}(P=0.287)$; by the end of the follow-up, lung involvement had substantially increased, with a 1.6-fold greater odds of lung metastases in the KRAS mut patients $(P=0.012$, 95\% CI 1.09-2.43; Figure 1). The liver was less frequent as the initial metastatic organ in patients with a KRAS mutation $(P=0.004)$. Among the 275 patients who initially had liver as the only site of metastatic disease, $K R A S^{\text {mut }}$ patients were two-fold more likely to develop lung metastasis $(P=0.007,95 \%$ CI 1.2-3.5; Table 1).

Among the 315 patients with thoracic metastasis, there were no differences in thoracic lymph node involvement $(P=0.18)$, number of lung metastases $(P=0.71)$, lung lobes involved $(P=0.19)$ or disease in bilateral lung $(P=0.27)$ by KRAS mutational status (Table 1). There were no statistically significant differences in lung metastasis frequency or pattern of KRAS mutations by codon $(12,13$ or 61); the distribution of mutations was consistent with those reported by prior studies (Supplementary Table 1).

Analysis of survival. Compared with $K R A S^{\mathrm{wt}}$ patients, $K R A S^{\text {mut }}$ patients had a shorter TTLM (22.4 vs 15.2 months; hazard ratio $(\mathrm{HR})=1.40 ; 95 \%$ CI $1.12-1.75 ; P=0.002$; Figure $2 \mathrm{~A})$ and LMFS (16.7 vs 12.9 months; $\mathrm{HR}=1.27 ; 95 \%$ CI $1.03-1.55 ; P=0.019$; Supplementary Figure 1). In the cohort of patients with initially liver-limited mCRC, TTLM was also shorter in KRAS ${ }^{\text {mut }}$ patients (33.1 vs 15.6 months; $\mathrm{HR}=1.82$; 95\% CI 1.34-2.49; $P<0.001$; Figure 2B). Overall survival was not different between the groups $(\mathrm{HR}=1.03 ; P=0.6$; Supplementary Figure 2).

\section{DISCUSSION}

To the best of our knowledge, with 494 patients included, this is the largest retrospective series to analyse the role of KRAS mutational status in pattern of pulmonary metastasis in CRC patients. Lung metastasis was more common at diagnosis of mCRC in patients whose primary tumour carried a KRAS mutation and more likely 
Table 1. Patient characteristics $(N=494)$ and the association between KRAS mutational status and metastatic patterns

\begin{tabular}{|c|c|c|c|}
\hline Variable & $\begin{array}{l}\text { KRAS }^{\mathrm{wt}} \\
292 \text { pts } \\
N(\%)\end{array}$ & $\begin{array}{l}\text { KRAS }^{\text {mut }} \\
202 \text { pts } \\
N(\%)\end{array}$ & $P$-value \\
\hline Age (years), median & 55 & 56 & 0.971 \\
\hline Sex & & & 0.063 \\
\hline $\begin{array}{l}\text { Male } \\
\text { Female }\end{array}$ & $\begin{array}{l}182(62 \%) \\
110(38 \%)\end{array}$ & $\begin{array}{r}109(54 \%) \\
93(46 \%)\end{array}$ & \\
\hline Location of primary tumour(s) & & & 0.01 \\
\hline $\begin{array}{l}\text { Ascending colon } \\
\text { Transverse colon } \\
\text { Descending colon/sigmoid } \\
\text { Rectum } \\
\text { Missing }\end{array}$ & $\begin{aligned} 66 & (23 \%) \\
16 & (5 \%) \\
147 & (50 \%) \\
61 & (21 \%) \\
& 2(\sim 1 \%)\end{aligned}$ & $\begin{array}{l}75(37 \%) \\
12(6 \%) \\
77(38 \%) \\
37(18 \%) \\
1(\sim 0 \%)\end{array}$ & \\
\hline $\begin{array}{l}\text { Location of primary tumour(s) - } \\
\text { right vs left colon }\end{array}$ & & & 0.001 \\
\hline $\begin{array}{l}\text { Right (ascending }+ \text { transverse) } \\
\text { Left (descending/sigmoid + rectum) } \\
\text { Missing }\end{array}$ & $\begin{array}{r}82(28 \%) \\
208(71 \%) \\
2(\sim 1 \%)\end{array}$ & $\begin{aligned} 87 & (43 \%) \\
114 & (57 \%) \\
1 & (\sim 0 \%)\end{aligned}$ & \\
\hline Tumour histology and grade & & & 0.318 \\
\hline $\begin{array}{l}\text { Well differentiated } \\
\text { Moderately differentiated } \\
\text { Poorly differentiated } \\
\text { Missing }\end{array}$ & $\begin{aligned} 2(\sim 1 \%) \\
191(65 \%) \\
84(29 \%) \\
15(5 \%)\end{aligned}$ & $\begin{array}{c}1(\sim 0 \%) \\
148(73 \%) \\
46(23 \%) \\
7(3 \%)\end{array}$ & \\
\hline Any type of synchronous disease & & & 0.570 \\
\hline $\begin{array}{l}\text { Yes } \\
\text { No }\end{array}$ & $\begin{array}{l}104(51 \%) \\
188(49 \%)\end{array}$ & $\begin{array}{r}77(38 \%) \\
125(62 \%)\end{array}$ & \\
\hline $\begin{array}{l}\text { Timing of pulmonary metastasis in } \\
\text { relation to primary tumour }\end{array}$ & & & 0.018 \\
\hline $\begin{array}{l}\text { Synchronous } \\
\text { Metachronous or absent }\end{array}$ & $\begin{array}{c}27(9 \%) \\
265(91 \%)\end{array}$ & $\begin{array}{r}33(16 \%) \\
169(84 \%)\end{array}$ & \\
\hline Lung involvement at diagnosis of $\mathrm{mCRC}$ & & & 0.287 \\
\hline $\begin{array}{l}\text { Yes } \\
\text { No }\end{array}$ & $\begin{array}{r}43(15 \%) \\
249(85 \%)\end{array}$ & $\begin{array}{r}37(18 \%) \\
165(82 \%)\end{array}$ & \\
\hline Lung involvement at last follow-up & & & 0.012 \\
\hline $\begin{array}{l}\text { Yes } \\
\text { No }\end{array}$ & $\begin{array}{l}173(59 \%) \\
119(41 \%)\end{array}$ & $\begin{array}{r}142(70 \%) \\
60(30 \%)\end{array}$ & \\
\hline Number of lung metastases ${ }^{a}$ & & & 0.71 \\
\hline $\begin{array}{l}\text { Single } \\
\text { Multiple }\end{array}$ & $\begin{array}{r}18(10 \%) \\
155(90 \%)\end{array}$ & $\begin{array}{c}13(9 \%) \\
129(91 \%)\end{array}$ & \\
\hline Lung lobes involved $^{a}$ & & & 0.19 \\
\hline $\begin{array}{l}1 \\
>1\end{array}$ & $\begin{array}{r}27(16 \%) \\
146(84 \%)\end{array}$ & $\begin{array}{r}15(11 \%) \\
127(89 \%)\end{array}$ & \\
\hline Laterality of pulmonary metastasis ${ }^{a}$ & & & 0.273 \\
\hline $\begin{array}{l}\text { Unilateral (right/left) } \\
\text { Bilateral }\end{array}$ & $\begin{array}{r}31(18 \%) \\
142(82 \%)\end{array}$ & $\begin{array}{r}19(12 \%) \\
123(88 \%)\end{array}$ & \\
\hline Thoracic lymph node & & & 0.184 \\
\hline $\begin{array}{l}\text { Involved } \\
\text { Not involved }\end{array}$ & $\begin{array}{r}68(23 \%) \\
224(77 \%)\end{array}$ & $\begin{array}{r}37(18 \%) \\
165(82 \%)\end{array}$ & \\
\hline Liver involvement at diagnosis of $\mathrm{mCRC}$ & & & 0.004 \\
\hline $\begin{array}{l}\text { Yes } \\
\text { No }\end{array}$ & $\begin{array}{r}228(78 \%) \\
64(22 \%)\end{array}$ & $\begin{array}{r}134(66 \%) \\
68(34 \%)\end{array}$ & \\
\hline $\begin{array}{l}\text { Patients with only liver disease at } \\
\text { diagnosis of } \mathrm{mCRC}^{\mathbf{b}}\end{array}$ & & & 0.007 \\
\hline $\begin{array}{l}\text { Lung metastasis } \\
\text { No lung metastasis }\end{array}$ & $\begin{array}{r}100(56 \%) \\
80(44 \%) \\
\end{array}$ & $\begin{array}{l}68(72 \%) \\
27(28 \%) \\
\end{array}$ & \\
\hline \multicolumn{4}{|c|}{$\begin{array}{l}\text { Abbreviation: } \mathrm{mCRC}=\text { metastatic colorectal carcinoma. } \\
{ }^{\text {a Among }} 315 \text { patients with thoracic metastasis. } \\
{ }^{\text {b}} \text { Among } 275 \text { patients who had liver as the only site of metastasis at diagnosis of mCRC. }\end{array}$} \\
\hline
\end{tabular}

to develop during the disease course, suggesting a potential metastatic tropism of CRC to the lung that may have clinical significance for treatment planning.

Despite the lack of difference in OS by KRAS mutational status in the general population of patients with mCRC, several studies

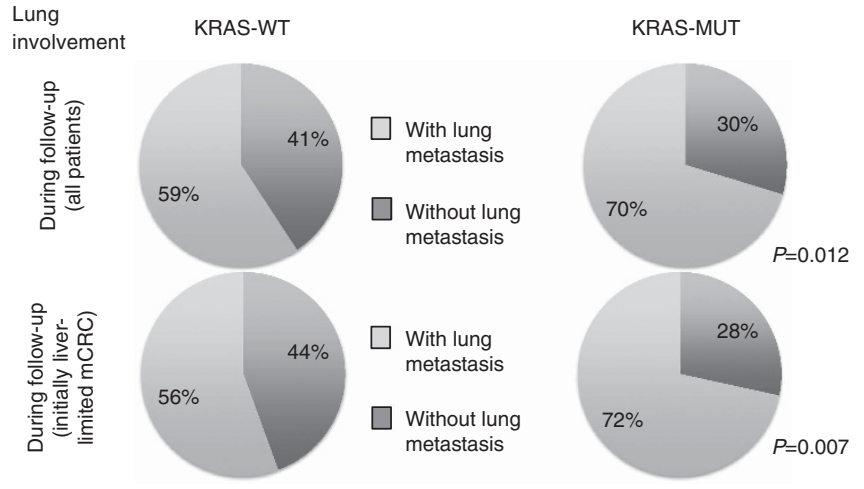

Figure 1. Lung involvement according to KRAS mutational during follow-up in all patients with $\mathrm{mCRC}$ and during follow-up for the cohort of patients with initially liver-limited $\mathrm{mCRC}$.

have shown that KRAS mutational status has a prognostic role in specific surgical populations, for example, in predicting the risk of recurrence in localised CRC (Hutchins et al, 2011) and after hepatic or lung resection (Vauthey et al, 2013; Schweiger et al, 2014). Our findings confirm the findings of Kim et al (2012) and Tie et al (2011), which identified differences in metastatic patterns according to KRAS status. Our study extends this finding to demonstrate that, in patients with liver-limited $\mathrm{mCRC}$ at diagnosis, lung metastasis is more likely to develop in patients with KRAS mutations. This finding provides validation of the recent report by Vauthey et al (2013) that demonstrated that rate of lung recurrence after hepatectomy is higher for tumours with a KRAS mutation, reiterating the potential clinical relevance of this mutation in selecting patients for surgical intervention.

Although our sample size is larger than those of other studies, our study does have a few limitations. First, it is a retrospective analysis of patients from a single institution and thus is subject to the bias of patterns of referral to major academic medical centres and could also explain the young median age observed, which reflects the population from the M.D. Anderson Cancer Center. However, the groups were well balanced according to age $(P=0.971-$ Table 1$)$ and, therefore, it was not a confounding factor in the analysis of end points between groups $\left(K R A S^{W T} v S\right.$ $K R A S^{M U T}$ ), with a low, if any, impact in the external validity of this study. Second, KRAS status was obtained from routinely available archival material and does not incorporate potential discordance in KRAS status between a primary tumour and its metastases. However, KRAS mutations are thought to be highly concordant during the progression of the disease (Artale et al, 2008; EtienneGrimaldi et al, 2008; Santini et al, 2008; Cejas et al, 2009). Third, the traditional sequencing (Sanger) method (with $\sim 20 \%$ allele frequency as lowest threshold for detection) or a mass spectroscopy method ( $\sim 15 \%$ allele frequency) for detection of KRAS mutations was used, both of which have lower sensitivity for mutation analysis than current next-generation sequencing approaches ( $\sim 5 \%$ allele frequency; Jimeno et al, 2009; Plesec and Hunt, 2009). However, the relevance of the additional low-allele frequency mutations revealed by the newer methodology is not clear and awaits for further validation.

While our analysis was limited to KRAS codons 12,13 and 61, KRAS codon 146 and NRAS codons 12, 13 and 61 may exhibit similar behaviour. Extended RAS testing including these codons has improved the predictive ability for EGFR monoclonal antibody therapy and is being incorporated into standard-of-care testing (Douillard et al, 2013; Stintzing et al, 2013). Collectively, the accumulating data suggest that the RAS mutations confer similar biology, but the association of extended RAS mutation with tropism to lungs remains to be defined. A few retrospective series 

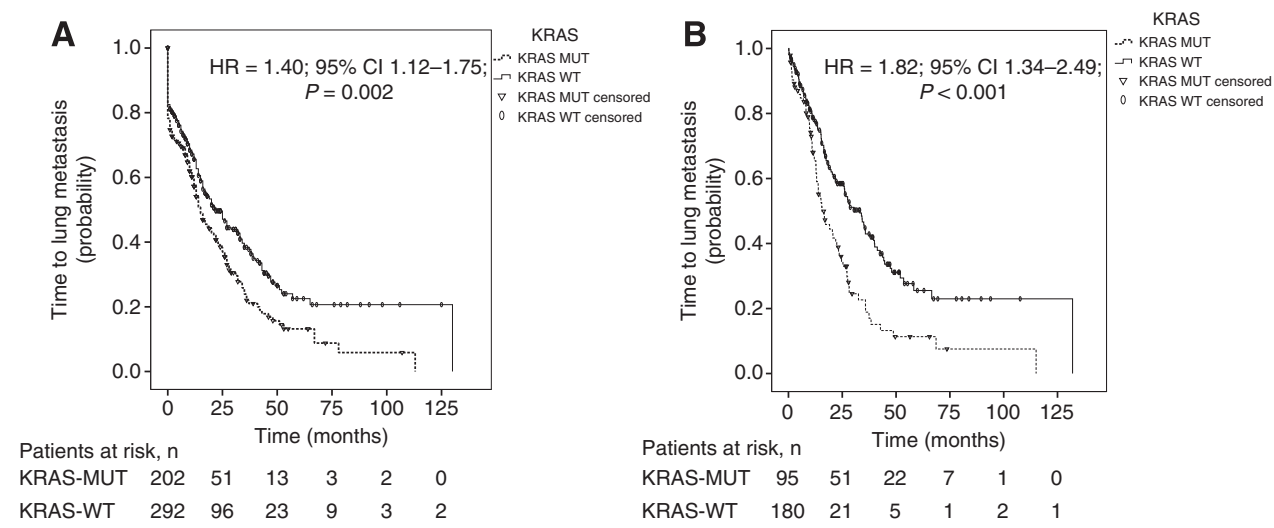

Figure 2. (A) Time-to-lung metastasis by KRAS mutational status in all patients and (B) in the cohort of patients with initially liver-limited mCRC.

have suggested heterogeneous behaviour among the types of KRAS mutation. More recently, Modest et al (2011) showed that, compared with mCRCs that have a KRAS codon 12 mutation, those with a codon 13 mutation present as more aggressive disease, with a statistically significantly higher rate of synchronous organ metastasis. Despite this, in our cohort there was no difference in lung metastasis frequency or pattern among cases with KRAS mutation in codons 12,13 or 61 .

These results support the conclusion that KRAS status can be used to risk stratify patients for development of pulmonary metastasis. Surveillance might be more focused on lung metastasis in patients with $K R A S^{\text {mut }}$ after curative locoregional treatment and when considering surgical options for oligometastatic disease.

\section{AUTHOR CONTRIBUTIONS}

All authors contributed to the conception and design, acquisition of data or analysis and interpretation of data, drafting the article or revising it critically for important intellectual content and final approval of the version to be published.

\section{CONFLICT OF INTEREST}

The authors declare no conflict of interest.

\section{REFERENCES}

Artale S, Sartore-Bianchi A, Veronese SM, Gambi V, Sarnataro CS, Gambacorta M, Lauricella C, Siena S (2008) Mutations of KRAS and BRAF in primary and matched metastatic sites of colorectal cancer. J Clin Oncol 26: 4217-4219.

Buo L, Meling GI, Karlsrud TS, Johansen HT, Aasen AO (1995) Antigen levels of urokinase plasminogen activator and its receptor at the tumor-host interface of colorectal adenocarcinomas are related to tumor aggressiveness. Hum Pathol 26: 1133-1138.

Cejas P, Lopez-Gomez M, Aguayo C, Madero R, de Castro Carpeño J, Belda-Iniesta C, Barriuso J, Moreno García V, Larrauri J, López R, Casado E, Gonzalez-Barón M, Feliu J (2009) KRAS mutations in primary colorectal cancer tumors and related metastases: a potential role in prediction of lung metastasis. PLoS One 4: e8199.

Douillard JY, Oliner KS, Siena S, Tabernero J, Burkes R, Barugel M, Humblet Y, Bodoky G, Cunningham D, Jassem J, Rivera F, Kocákova I, Ruff P, Błasińska-Morawiec M, Šmakal M, Canon JL, Rother M, Williams R, Rong A, Wiezorek J, Sidhu R, Patterson SD (2013) Panitumumab-FOLFOX4 treatment and RAS mutations in colorectal cancer. New Engl J Med 369: 1023-1034

Etienne-Grimaldi MC, Formento JL, Francoual M, François E, Formento P, Renée N, Laurent-Puig P, Chazal M, Benchimol D, Delpero JR, Letoublon C, Pezet D, Seitz JF, Milano G (2008) K-Ras mutations and treatment outcome in colorectal cancer patients receiving exclusive fluoropyrimidine therapy. Clin Cancer Res 14: 4830-4835.

Hutchins G, Southward K, Handley K, François E, Formento P, Renée N, Laurent-Puig P, Chazal M, Benchimol D, Delpero JR, Letoublon C, Pezet D, Seitz JF, Milano G (2011) Value of mismatch repair, KRAS, and BRAF mutations in predicting recurrence and benefits from chemotherapy in colorectal cancer. J Clin Oncol 29: 1261-1270.

Jankun J, Maher VM, McCormick JJ (1991) Malignant transformation of human fibroblasts correlates with increased activity of receptor-bound plasminogen activator. Cancer Res 51: 1221-1226.

Jimeno A, Messersmith WA, Hirsch FR, Franklin WA, Eckhardt SG (2009) KRAS mutations and sensitivity to epidermal growth factor receptor inhibitors in colorectal cancer: practical application of patient selection. J Clin Oncol 27: 1130-1136.

Kim MJ, Lee HS, Kim JH, Kim YJ, Kwon JH, Lee JO, Bang SM, Park KU, Kim DW, Kang SB, Kim JS, Lee JS, Lee KW (2012) Different metastatic pattern according to the KRAS mutational status and site-specific discordance of KRAS status in patients with colorectal cancer. $B M C$ Cancer 12: 347.

Leevers SJ, Marshall CJ (1992) Activation of extracellular signal-regulated kinase, ERK2, by p21ras oncoprotein. EMBO J 11: 569-574.

Lievre A, Bachet JB, Le Corre D, Boige V, Landi B, Emile JF, Côté JF, Tomasic G, Penna C, Ducreux M, Rougier P, Penault-Llorca F, Laurent-Puig P (2006) KRAS mutation status is predictive of response to cetuximab therapy in colorectal cancer. Cancer Res 66: 3992-3995.

Manfredi S, Bouvier AM, Lepage C, Hatem C, Dancourt V, Faivre J (2006) Incidence and patterns of recurrence after resection for cure of colonic cancer in a well defined population. Br J Surg 93: 1115-1122.

Mitry E, Guiu B, Cosconea S, Jooste V, Faivre J, Bouvier AM (2010) Epidemiology, management and prognosis of colorectal cancer with lung metastases: a 30-year population-based study. Gut 59: 1383-1388.

Modest DP, Stintzing S, Laubender RP, Neumann J, Jung A, Giessen C, Haas M, Aubele P, Schulz C, Boeck S, Stemmler HJ, Kirchner T, Heinemann V (2011) Clinical characterization of patients with metastatic colorectal cancer depending on the KRAS status. Anticancer Drugs 22: 913-918.

Nash GM, Gimbel M, Cohen AM, Zeng ZS, Ndubuisi MI, Nathanson DR, Ott J, Barany F, Paty PB (2010) KRAS mutation and microsatellite instability: two genetic markers of early tumor development that influence the prognosis of colorectal cancer. Ann Surg Oncol 17: 416-424.

Plesec TP, Hunt JL (2009) KRAS mutation testing in colorectal cancer. Adv Anat Pathol 16: 196-203.

Roth AD, Tejpar S, Delorenzi M, Yan P, Fiocca R, Klingbiel D, Dietrich D, Biesmans B, Bodoky G, Barone C, Aranda E, Nordlinger B, Cisar L, Labianca R, Cunningham D, Van Cutsem E, Bosman F (2010) Prognostic role of KRAS and BRAF in stage II and III resected colon cancer: results of the translational study on the PETACC-3, EORTC 40993, SAKK 60-00 trial. J Clin Oncol 28: 466-474.

Santini D, Loupakis F, Vincenzi B, Floriani I, Stasi I, Canestrari E, Rulli E, Maltese PE, Andreoni F, Masi G, Graziano F, Baldi GG, Salvatore L, Russo A, Perrone G, Tommasino MR, Magnani M, Falcone A, Tonini G, Ruzzo A (2008) High concordance of KRAS status between primary colorectal tumors and related metastatic sites: implications for clinical practice. Oncologist 13: 1270-1275.

Schweiger T, Hegedus B, Nikolowsky C, Hegedüs Z, Szirtes I, Mair R, Birner P, Döme B, Lang G, Klepetko W, Ankersmit HJ, Hoetzenecker K 
(2014) EGFR, BRAF and KRAS status in patients undergoing pulmonary metastasectomy from primary colorectal carcinoma: a prospective follow-up study. Ann Surg Oncol 21: 946-954.

Siegel R, Naishadham D, Jemal A (2013) Cancer statistics, 2013. CA Cancer J Clin 63: 11-30.

Siena S, Sartore-Bianchi A, Di Nicolantonio F, Balfour J, Bardelli A (2009) Biomarkers predicting clinical outcome of epidermal growth factor receptor-targeted therapy in metastatic colorectal cancer. J Natl Cancer Inst 101: 1308-1324.

Stintzing S, Jung A, Rossius L et al. (2013) Analysis of KRAS/NRAS and BRAF mutations in FIRE-3: a randomized phase III study of FOLFIRI plus cetuximab or bevacizumab as first-line treatment for wild-type (WT) KRAS (exon 2) metastatic colorectal cancer (mCRC) patients. Presented at the European Cancer Congress 2013; 28 September 28 2013; Amsterdam, The Netherlands. Abstract 17.

Tie J, Lipton L, Desai J, Gibbs P, Jorissen RN, Christie M, Drummond KJ, Thomson BN, Usatoff V, Evans PM, Pick AW, Knight S, Carne PW, Berry R, Polglase A, McMurrick P, Zhao Q, Busam D, Strausberg RL,
Domingo E, Tomlinson IP, Midgley R, Kerr D, Sieber OM (2011) KRAS mutation is associated with lung metastasis in patients with curatively resected colorectal cancer. Clin Cancer Res 17: 1122-1130.

Vauthey JN, Zimmitti G, Kopetz SE, Shindoh J, Chen SS, Andreou A, Curley SA, Aloia TA, Maru DM (2013) RAS mutation status predicts survival and patterns of recurrence in patients undergoing hepatectomy for colorectal liver metastases. Ann Surg 258: 619-626discussion 626-617.

Watanabe K, Saito N, Sugito M, Ito M, Kobayashi A, Nishizawa Y (2013) Incidence and predictive factors for pulmonary metastases after curative resection of colon cancer. Ann Surg Oncol 20: 1374-1380.

Wood KW, Sarnecki C, Roberts TM, Blenis J. (1992) ras mediates nerve growth factor receptor modulation of three signal-transducing protein kinases: MAP kinase, Raf-1, and RSK. Cell 68: 1041-1050.

Yamamoto H, Itoh F, Senota A, Adachi Y, Yoshimoto M, Endoh T, Hinoda Y, Yachi A, Imai K (1995) Expression of matrix metalloproteinase matrilysin (MMP-7) was induced by activated Ki-ras via AP-1 activation in SW1417 colon cancer cells. J Clin Lab Anal 9: 297-301.

Supplementary Information accompanies this paper on British Journal of Cancer website (http://www.nature.com/bjc) 